\title{
UNA PROPUESTA EDUCATIVA PARA LA FORMACIÓN EN VALORES DESDE EL FILME EL ENEMIGO DEL PUEBLO
}

\author{
AN EDUCATIONAL PROPOSAL FOR TRAINING IN VALUES FROM \\ THE FILM THE ENEMY OF THE PEOPLE
}

\section{M. ${ }^{a}$ Ángeles Almacellas Bernadó ${ }^{a}$ Eduardo Martínez Gómez ${ }^{b}$ y Carmen Pereira Domínguez ${ }^{c^{*}}$}

Fechas de recepción y aceptación: 5 de noviembre de 2020 y 9 de diciembre de 2020

DOI: https://doi.org/10.46583/edetania_2021.59.758

Resumen: Este trabajo se inicia con un breve marco introductorio sobre la realidad geográfica, política y social de finales del siglo xIx en Europa con el objeto de contextualizar el filme basado en la obra homónima de Ibsen, El enemigo del pueblo. Trata la historia de un médico de firmes principios que descubre una bacteria contaminante en las aguas del balneario de su pueblo, hecho que no solo pondrá en riesgo la salud de los vecinos y visitantes, sino que también originará un confrontamiento de intereses económicos y políticos. Esta trama fílmica, aún vigente, conlleva una serie de problemáticas éticas, culturales y sociopolíticas de aquel tiempo que resultan fácilmente trasladables a la realidad del mundo actual.

Entendemos que, a partir del filme, se puede organizar una propuesta educativa que consistiría en un análisis educativo, un estudio ejemplificado de valores (verdad, responsabilidad, deontología profesional y justicia), actividades educativas como la lectura de la obra literaria y su representación teatral y la educación democrática como medio de formar a personas libres y autónomas. En las reflexiones finales se valora la propuesta educativa desarrollada, así como

a Profesora Fundación López Quintás para el fomento de la creatividad y los valores.

${ }^{\mathrm{b}}$ Asesor cultural del Máster Oficial de Psicopedagogía. Centro Universitario Internacional de Barcelona. Universidad de Barcelona.

${ }^{\mathrm{c}}$ Departamento de Análisis e Intervención Psicoeducativa. Universidad de Vigo.

*Correspondencia: Universidad de Vigo. Facultad de Ciencias de la Educación. Campus de Ourense. Campus da Auga. Edificio Facultades, Campus As Lagoas. s/n, 32004 Ourense. España.

E-mail: mcdguez@uvigo.es 
las alternativas de futuro que considerar en posteriores investigaciones. Finalizamos con las referencias bibliográficas acordes con el tema de estudio.

Palabras clave: propuesta educativa, cine, mirada pedagógica, docente, adolescencia, verdad, responsabilidad, libertad, ética profesional, justicia, educación democrática.

Abstract: This work begins with a brief introductory framework on the geographical, political and social reality of the late nineteenth century in Europe in order to contextualize the film based on Ibsen's homonymous work, The enemy of the people. It is the story of a doctor of solid principles who discovers a contaminating bacterium in the waters of his town's spa, a fact that will not only put the health of neighbors and visitors at risk but will also lead to a confrontation of economic and political interests. This film plot, still in force, involves a series of ethical, cultural and socio-political problems that are easily transferable to the reality of the current world.

We understand that, after watching the film, an educational proposal can be organized that would consist of an educational analysis, an exemplified study of values (truth, responsibility, professional deontology and justice), educational activities such as the reading of the literary work and its theatrical representation and democratic education as a means of training free and autonomous people. In the final reflections, the educational proposal developed is evaluated, as well as the alternatives for the future to be considered in subsequent research. We finish with the bibliographic references according to the topic.

Keywords: educational proposal, cinema, pedagogical view, teacher, adolescence, truth, responsibility, freedom, professional ethics, justice, democratic education.

A pesar de ser un solitario, mi conciencia de pertenecer a la comunidad invisible de aquellos que luchan por la verdad, la belleza y la justicia me ha impedido sentirme aislado.

Albert Einstein ${ }^{1}$.

\section{INTRODUCCIÓN}

La película El enemigo del pueblo fue dirigida por George Schaefer ${ }^{2}$ y protagonizada por el actor y productor Steve McQueen en 1978. El guionista

\footnotetext{
${ }^{1}$ Recuperado de: "Einstein, filósofo sin querer": https://www.filco.es/einstein-filosofo-sin-querer/ (consulta: 5/10/2020).

${ }^{2}$ Ficha técnica de la película: Título original: An enemy of the people. Año: 1978. Pais: Estados Unidos. Director: George Schaefer. Guion: Alexander Jacobs, Arthur Miller (Obra: Henrik Ibsen).
} 
es Alexander Jacobs, que sigue punto por punto la adaptación realizada por el dramaturgo Arthur Miller en 1950 de la obra original y homónima del noruego Henrik Ibsen, escrita en 1882 bajo el título original de En Folkefiende.

Schaefer ${ }^{3}$ fue dueño de una larga trayectoria como realizador televisivo y defendió eficazmente el libreto original de Ibsen adaptado por Miller ${ }^{4}$. Con todo, posiblemente vio supeditada su labor al lucimiento de la estrella que hizo viable la película, un McQueen ${ }^{5}$ que también se encargó de la producción ejecutiva de El enemigo del pueblo.

Inevitablemente, las circunstancias culturales, políticas y sociales de una época influyen en el contenido de las obras surgidas durante ese momento histórico. En este caso, El enemigo del pueblo no es, a pesar de su universalidad, una excepción. La localidad noruega en la que tienen lugar tanto la acción del libro de Ibsen como la de su posterior readaptación teatral y cinematográfica, es un fiel reflejo de un continente, el europeo, que avanzaba de forma titubeante, pero sin desviarse, hacia la democracia moderna. El eco de la Revolución francesa, que tuvo su violento inicio en 1789 e instauró numerosos e importantes cambios durante la siguiente década, aún estaba presente en la Europa de finales del siglo XIX. A menos de un siglo de su nacimiento, libertad, igualdad y fraternidad habían pasado de ser lemas revolucionarios estrictamente franceses a pautas sociales, políticas y económicas que seguir por muchas de las sociedades europeas del momento.

Duración: 103+ minutos. Música: Leonard Rosenman. Fotografía: Paul Lohmann. Reparto: Steve McQueen (doctor Thomas Stockmann), Bibi Andersson (Catherine Stockmann), Charles Durning (Peter Stockmann), Richard Dysart (Aslaksen), Michael Cristofer (Hovstad), Michael Higgins (Billing), Eric Christmas (Morten Kiil), Robin Pearson Rose (Petra Stockmann), Richard Bradford (Captain Forster), John Levin (Ejlif Stockmann), Ham Larsen (Morten Stockmann), Louise Hoven (Randine). Productora: First Artists / Solar Productions. Género: Drama, Siglo XXI, Política.

Recuperado de: https://www.filmaffinity.com/es/film633030.html. Tráiler: https://www.youtube. com/watch?v=WRO9WXpPOIE (consulta: 5/10/2020).

${ }^{3}$ Sobre George Schaefer. Recuperado de: https://es.wikipedia.org/wiki/George_Schaefer (consulta: $5 / 10 / 2020$ ).

${ }^{4}$ Sobre Arthur Miller: Daba, R. (2018). Antología de páginas inolvidables: Arthur Miller. Recuperado de: https://blogs.elespectador.com/cultura/corazon-de-pantaleon/antologia-paginas-inolvidablesarthur-miller-11 (consulta: 5/10/2020).

${ }^{5}$ Sobre Steve McQueen. Recuperado de: https://es.wikipedia.org/wiki/Steve_McQueen y https:// stevemcqueen.com/\#advertising (consulta: 5/10/2020). 
Durante este periodo, algunos escritores y figuras públicas masculinas defendieron esa igualdad de derechos entre hombres y mujeres. Y gracias a su constante cuestionamiento del patriarcado como modelo social, Ibsen se convirtió en uno de ellos. Consecuentemente generó una notable polémica alrededor del contenido social y la orientación política de su obra. La mujer oprimida por diferentes convenciones sociales, políticas y económicas pasó a ser una de las figuras recurrentes de su obra, necesaria en un momento histórico en el que a la igualdad entre hombres y mujeres aún le quedaba un largo camino por recorrer ${ }^{6}$.

La Revolución Industrial impulsó enormemente la economía en los países donde se implantó, provocando un importante descenso de la mortalidad gracias a que la regularidad de la producción permitió una mejor y más abundante alimentación. La producción se masificó y, pese a los numerosos problemas sociales surgidos a raíz de este incremento productivo y la mala repartición de los beneficios resultantes, la riqueza personal de una parte significativa de la población se consolidó. Como consecuencia de este nuevo paradigma, surgieron nuevas clases económicas como la clase media o la burguesía y su antónimo socioeconómico, el proletariado.

Esta ideologización de la vida social y política se vio refrendada por el apogeo de la prensa que, a lo largo del siglo XIX afianzó su capacidad de influencia como cuarto poder, complementando los otros tres poderes inherentes al estado de derecho: el poder ejecutivo, el poder legislativo y el poder judicial. La regularidad editora de la prensa fue otra de las consecuencias de la industrialización social. Resultó conveniente para la creación de diversos estados de opinión que, al menos sobre el papel, debían salvaguardar la pluralidad que se le presuponía a todo régimen democrático.

La apropiación del poder desde la ciudadanía, a través de su voto y participación en casos que le afectaban de forma más o menos directa, también supuso un debilitamiento de estamentos e implicó la importante caída en desgracia de estamentos como el eclesiástico, el surgimiento de movimientos como el comunismo o el anarquismo. Este auge y revalorización de la ciencia como

${ }^{6}$ Sobre Henrik Ibsen: SIRJACQ, L.C. (2013). Ibsen superstar. Le Monde diplomatique, 16, p. 24. Recuperado de: https://www.monde-diplomatique.fr/2013/10/SIRJACQ/49717. Consulta: 5 de octubre de 2020 . 
sinónimo de progreso y verdad se personificó en El enemigo del pueblo en el honesto y avanzado doctor Stockmann. Pero su figura no es la única que destila parte del espíritu de su época, que habla a través de él.

El enemigo del pueblo se considera la obra más "social" de Ibsen. Esta adaptación cinematográfica muestra, como ya hacía la versión teatral de Miller, algunas de las líneas de pensamiento o estratos sociales que conformaban la vida política, social y económica noruegas de finales del siglo XIX a través de sus personajes. Así, analizando su ordenamiento y papel en la obra, podremos estudiar la postura de Ibsen, rabiosamente crítica, ante una época que se pretendía nueva pero que arrastraba inconscientemente muchos de los males de un pasado marcado por el autoritarismo (Anderson-Imbert, 1946).

El filme El enemigo del pueblo ${ }^{7}$ sobresale tanto por su calidad cinematográfica como por el tema que aborda y, aunque se desarrolla a final del siglo XIX, mantiene una gran vigencia con otras problemáticas de nuestra época (Martínez, 2016).

\section{UnA PRopuesta EDUCATIVA A PARTIR DEL FILME EL ENEMIGO DEL PUEBLO}

Analizaremos la obra literaria llevada a la gran pantalla y deduciremos los valores que concurren en las diversas escenas y diálogos de la película asociada a actividades como la lectura de la obra y su representación teatral y la educación democrática como medio de formar a personas libres y autónomas.

La imagen de apertura nos transmite de inmediato el ambiente del que parte la historia que se va a desarrollar: la casa de la familia del doctor Thomas Stockmann es un hogar feliz abierto a los demás. Su esposa, Catherine, con gesto sereno y sonrisa en los labios, está preparando una mesa para los invitados.

Muy al principio, una frase de Peter Stockmann, el alcalde, anuncia el tema de la película, es decir, la raíz del conflicto que va a desencadenarse: "El individuo tiene que subordinarse al bien general, o, mejor dicho, a las autoridades que tienen a su cargo el bien común" (00:09:29). Esto es lo que va a debatirse en el filme: si todo hombre debe subordinarse a los gobernantes legítimos en

${ }^{7}$ MEDICINAYCINE, “Un enemigo del pueblo". Recuperado de: http://medicinaycine.blogspot. com/2017/06/un-enemigo-del-pueblo.html (consulta: 5/10/2020). 
cualesquiera circunstancias o bien si debe correr el riesgo de enfrentarse al poder cuando lo legal no se corresponde con lo ético y opta decididamente por la verdad y la libertad. Como concreciones del tema central, se van a tratar otros subtemas de gran interés que abren grandes preguntas para la reflexión (Almacellas, 2015; Orellana, Almacellas y Watt, 2019). Las siguientes dos primeras cuestiones solo quedan planteadas, mientras que las dos últimas, referentes a la manipulación y a la comunidad/masa, tienen respuesta en el filme.

- ¿Es legítimo intentar alcanzar un objetivo bueno en sí mismo (las ganancias que el balneario supondría para el pueblo), pero que implica efectos colaterales perniciosos (las enfermedades de los usuarios del balneario)? Se trata de la vieja cuestión sobre si el fin puede justificar los medios.

- ¿Cuál debería ser la función de la prensa en una sociedad? ¿Existe la prensa absolutamente libre y veraz?

- ¿Cómo manipula a un colectivo el ambicioso de poder? ¿Por qué y para qué lo hace? ¿Qué medios utiliza?

- ¿Cuál es la diferencia entre "comunidad” de personas y "masa" de personas?

La acción transcurre en un lapso breve - dos o tres días como máximo-y la narración es lineal, sin recurrir al flashback ni a los saltos en el tiempo. El relato está estructurado en tres apartados que se corresponden con las distintas etapas y facetas del desarrollo de la historia, tanto en el nivel de la acción argumental, como en la dimensión profunda del contenido humano del conflicto. El corte entre dichas etapas no es neto y drástico sino que veremos unos espacios de transición.

\subsection{Planteamiento del argumento y presentación de los personajes (00:02:18-00:15:38).}

\subsubsection{Protagonista y antagonista}

En los primeros quince minutos, nos presentan al honrado y decidido Thomas Stockmann, y a su malvado antagonista, su hermano, Peter Stockmann. En poco tiempo, nos dan a conocer sus rasgos personales, sus opciones de vida y 
sus debilidades, y cómo se sitúa cada uno de ellos respecto de la realidad del balneario que constituirá el detonante del conflicto.

Thomas es el paradigma del hombre de valores con una conciencia limpia y recta. Junto a su mujer Catherine han creado una familia que rezuma amor y felicidad. Viven una época de relativa bonanza económica, después de un tiempo duro de penurias y privaciones. Su hogar es un ámbito abierto de relaciones cálidas y afectuosas en el que todo el mundo es siempre bien acogido (López-Quintás, 2009).

Thomas no es un idealista soñador que descuida las necesidades básicas de su familia, no es un derrochador, como pretende insinuar su hermano Peter. Se ocupa de ganar dinero, pero para él, los bienes materiales son simplemente un medio para mantener a su familia con dignidad. Los integra en un proyecto de vida superior donde priman las relaciones humanas valiosas.

Peter, el antagonista, es un ambicioso del mando, un hombre sin escrúpulos y un hábil manipulador (López-Quintás, 2001). Su vida está centrada en su rol de alcalde.

\subsubsection{El conflicto}

Ante las dudas de una posible insalubridad de las aguas del balneario, con el consiguiente peligro para la salud de las personas, Thomas, como experto en sanidad, hace las averiguaciones necesarias para conocer la verdad. Después busca de inmediato una solución ética adecuada a la situación que sería la reconstrucción total de todo el sistema de conducción del agua.

Sin embargo, el alcalde pretende hacer caso omiso de la información sobre los graves daños que supondría utilizar un agua infectada porque asumir el programa propuesto por el médico implicaría:

- Reconocer que los gobernantes de la ciudad gestionaron mal la construcción de las canalizaciones del agua, a pesar de las reiteradas advertencias del doctor Stockmann y, por tanto, ellos son los responsables de lo que ahora está sucediendo.

- Acometer una obra de renovación de las tuberías, lo cual supondría un costo económico elevado, que recaería de lleno sobre la población, con un gran aumento de los impuestos. 
- Perder todos los beneficios inmediatos que podría aportar el balneario, incluso, tener que renunciar definitivamente a las ganancias.

La afirmación de Peter: "Cuanta más gente conozca el balneario, mejor”, y la objeción de Thomas: "En situación normal, estaría de acuerdo" (00:08:36), constituyen simples frases que nos hacen intuir por dónde va a ir el hilo argumental del enfrentamiento entre los dos hermanos y que lo que va a estar en juego a través de ellos será la verdad frente a la mentira, la honradez frente a la infamia, la libertad frente a la manipulación.

\subsubsection{Personajes}

Hovstad, director del periódico local La voz del pueblo, Billing, redactor, y Aslaksen representan el mundo de la prensa, el cuarto poder. Afirman sentirse en la obligación de que el pueblo esté informado y hacen alarde de estar comprometidos con la verdad y la libertad. Sin embargo, llegado el momento de tener que optar, no dudarán en ponerse al servicio del dinero y el poder.

El capitán George Forster simboliza a quien no quiere integrarse en una sociedad que siente como ajena. Intenta mantenerse al margen sin comprometerse. Finalmente, no puede evadirse y la misma sociedad a la que despreciaba acaba engulléndolo.

El señor Kiil, padre de Catherine, es el personaje que no se involucra pero se aprovecha de la situación creada por otros. No quiere vivir con la familia de su hija ni participar de sus reuniones, prefiere su independencia.

Luego, en el tenso escenario creado en el pueblo, veremos que el señor Kiil ni defiende el bien ni provoca el mal, deja que los otros lo hagan y por último se vale de la situación para su propio beneficio.

El pueblo: no tiene entidad. Es un grupo manipulable, gente mediocre, sin criterios claros ni sentido ético. No solo Peter, sino incluso el articulista Aslaksen, un hombre pusilánime, no duda en afirmar que puede gestionar la opinión del pueblo y decidir el partido que vaya a tomar en el conflicto entre el médico y el alcalde. Se habla del pueblo como de una masa dispuesta a cumplir mansamente las pautas que le dicten, sin percatarse de que quien dicta es un 
dictador. Los ciudadanos se dejan manipular sin resistencia, mientras siguen viviendo ingenuamente la ilusión de estar actuando libremente.

2.1.4 Transición al segundo apartado: desencadenante de la acción y toma de postura del protagonista (00:15:38 - 00:31:40).

Hasta ese momento, la existencia de Thomas Stockmann había sido apacible y feliz. Había sabido crear un ámbito de vida éticamente valioso y en su entorno reinaba el orden y la armonía. Se sentía un rey, con algo por lo que luchar, por lo que trabajar, algo que mejorar. El pueblo tenía perspectivas de crecer, de elevar su nivel de vida gracias a los efectos del balneario.

Pero de súbito, una fatal noticia viene a desbaratarlo todo y ese mundo idílico podría saltar por los aires. El informe del laboratorio de la Universidad confirma las sospechas del médico: "El balneario milagroso que ha costado una fortuna es un pozo negro, una fuente inagotable de infecciones" (00:17:58). El mundo sereno y prometedor en el que transcurrían sus días corre el riesgo de tambalearse por una información de la que solo él es depositario. No puede eludir la respuesta, debe decidir cómo va a situarse ante la realidad.

El periodista Hovstad, sobrecogido, hace la pregunta decisiva: "¿Qué hará ahora, doctor?". Él responde contundente: "Remediarlo" (00:18:53). Es toda una declaración de principios, no admite réplica. Su actitud es clara.

De momento, la prensa apoya al facultativo con decisión y hasta plantea hacerle un homenaje popular. Le garantiza el respaldo de los industriales de la zona y de la población en general. Parece que nada substancial ha cambiado en su vida. ¿Pero cuál será la reacción del antagonista?

\subsection{Núcleo de la acción: las fuerzas del mal acosan con violencia al protagonista (00:31:48 - 01:20:40).}

En esta segunda etapa, el mundo del protagonista está alterado como consecuencia del conflicto planteado. Ahora prevalece la opción por el interés espurio en detrimento de la ética. 
La visita del regidor Peter a su hermano marca el momento en que todo el mundo feliz del médico puede venirse abajo si no cambia de actitud. Contra lo que Thomas esperaba, Peter está muy enojado con él. Le reprocha que no haya pensado en el dinero que supone el balneario para la ciudad. "En tus manos está la ruina de tu propia ciudad", le dice. Es una situación tremenda. "Yo no quiero arruinar nada. - responde Thomas atribulado- ¿Qué se puede hacer?" (00:33:58).

\subsubsection{El protagonista contra las cuerdas}

El alcalde no está dispuesto a cambiar ni un ápice en la hoja de ruta de la explotación del balneario y el doctor deberá replantearse su actitud. Para hacerse con la voluntad de su hermano Thomas, Peter empieza a desplegar su estrategia en tres tiempos.

1. Primero presenta una cara amable, como si le comprendiera y estuviera de su lado. Intenta facilitarle una actitud conciliadora para su conciencia: le permitirían hacer algunas mejoras a cambio de su silencio: "Si eres razonable y actúas con discreción, la directiva estará dispuesta a poner a tu disposición todos los medios para mejorar las instalaciones, sin sacrificios innecesarios" (00:34:26 - 00:34:41).

2. Después, a modo de chantaje emocional, alude al bien de la ciudad: "Supongamos que es cierto. No me importa tanto mi reputación como el bien de la ciudad. Sin autoridad moral no hay gobierno. Y esta es la razón que me obliga a evitar que tu informe llegue a la junta directiva. Más adelante yo plantearé el asunto. Mientras tanto, no debe trascender nada al pueblo" (00:35:01 - 00:35:17).

3. A continuación, recurre al autoritarismo, las amenazas y los insultos: “Sabes las consecuencias que puede tener para ti y para tu familia? [...]. Te voy a dar una orden. Y te aviso, obedécela si valoras en algo tu propia carrera” (00:35:37). “¡Un traidor! ¡Me traicionas a mí, a tu familia y a toda la ciudad!” (00:38:08).

Catherine está tan asustada por la violencia de su cuñado, que también intenta que su marido abandone el asunto. Su actitud pone de relieve la soledad 
del héroe que, bajo su única responsabilidad, deberá tomar una decisión cuyas consecuencias no repercutirán solo sobre sí mismo, sino que tendrá efectos sobre las personas de su entorno. Si no atiende a los requerimientos de su hermano Peter y permanece fiel a sus principios éticos, puede que tenga que arrostrar terribles daños para su familia. Thomas debe reflexionar con rigor antes de determinarse.

Thomas no se da por vencido. Sin embargo, en su actitud valiente no hay nada de empecinamiento, ni de revanchismo o de ira. Está resuelto a luchar por la verdad y para que se haga lo correcto, pero no está dispuesto a batallar contra nadie. Si así lo hiciera, si considerara a Peter un enemigo contra el que pelear, automáticamente él mismo se rebajaría y se convertiría a su vez en enemigo de alguien. Pero Thomas es un hombre de valores y no se deja caer al nivel rastrero de los enfrentamientos personales. De ahí que el insulto que le van a arrojar -y que da título a la obra y al filme-, enemigo del pueblo, sea tan injusto.

Tampoco hay en él ningún atisbo de soberbia intelectual al defender a ultranza la verdad que ha descubierto, no pretende que se reconozca su razón. Sin embargo, está dispuesto a luchar para evitar los riesgos y los perjuicios de un proyecto basado en las mentiras y la corrupción.

Ciertamente Thomas es un hombre veraz, auténtico. Se ve en él coherencia entre lo que piensa, lo que dice y lo que hace. Por eso es digno de confianza, con él nadie puede llamarse a engaño. Pero eso mismo lo convierte en alguien vulnerable. En una pugna entre las fuerzas del mal y las fuerzas del bien, se nos viene a decir que el mal siempre es más poderoso y acaba arrollando al bien. En cambio, el mal nunca puede alcanzar la victoria total y definitiva, porque el bien es un valor y se mueve en un nivel superior, en el que resulta inalcanzable e indestructible. A Thomas podrán quebrarlo, pero no lo doblegarán. Cabría reducir el cerco hasta debilitarlo, pero su libertad interior es inalcanzable.

\subsubsection{La prensa, ¿libre y veraz?}

Peter Stockmann desarrolla una eficaz labor de manipulación y logra que los periodistas, como sucederá luego con las personas del pueblo, adopten una actitud beligerante frente a Thomas. Parece imposible con unos periodistas que alardeaban de estar dispuestos a defender la verdad y la libertad. ¿Cómo lo consigue? 
Se dirige a la redacción de La voz del pueblo siguiendo la misma táctica de manipulación que antes con su hermano:

- Primero presenta una cara amable, intenta halagarles para hacerse el simpático: "Qué limpio. Siempre imaginé que este local estaría sucio, pero no lo está" (00:49:07).

- Después, también a modo de coacción, apela al bien de los ciudadanos, que se verían obligados a admitir la pesada carga de un aumento de impuestos: "Será el municipio el que asuma todos los gastos relacionados con el balneario. Si los ciudadanos desean cambiarlo, naturalmente tendrán que pagar" (00:51:25).

- A continuación, recurre al autoritarismo, las amenazas y las descalificaciones: “¡Es un hecho! Y el balneario permanecerá cerrado dos años... ¡Y todo por una infección imaginaria!” (00:51:57 - 00:52:28). Acusa a su hermano de haber actuado dolosamente, "por rencor, por odio hacia la autoridad y nada más". Cuando ya los tiene doblegados, para asegurarse la presa, miente abiertamente sin ningún pudor: "Todo esto no tiene nada que ver con la salud pública, sino con el simple deseo de destrucción" (00:52:38). Por último, hace un velado alarde de fuerza que encierra un tono amenazador hacia el periódico: "Espero que la gente lo entienda tal como es" (00:52:52).

Los tres periodistas están atemorizados porque no se habían percatado de que, si prevalece la verdad, los sacrificios van a ser duros y ellos mismos no van a salir indemnes. Estaban decididos a apoyar la verdad y el bien, mientras a ellos no les supusiera ningún perjuicio, pero en cuanto han comprendido que el alcalde es más poderoso que ellos y es capaz de hundirlos, cambian radicalmente de actitud, "No creí que tuviéramos que pagar más impuestos" (00:53:23). "No pienso sacrificar este periódico" (00:58:34).

\subsubsection{Carácter siniestro de la manipulación}

El doctor Stockmann ha convocado al pueblo en casa del capitán Forster para informar sobre el estado del balneario. El alcalde acude también. Todo tiene la apariencia de una reunión legítima, para que la población esté bien 
informada y pueda formarse su propia opinión. Pero Peter, el demagogo, nunca juega limpio. Lo tiene todo bien calculado, su plan está minuciosamente trazado. Cuenta, además, con un cómplice muy eficaz: la prensa.

Una vez más, sigue su estrategia manipuladora en tres tiempos:

1. Primero presenta su cara más amable. Entra afable, saludando a todo el mundo. Aparentemente, es un hombre dialogante, que quiere que las cosas se hagan bien, en democracia.

2. Thomas llega también dispuesto a exponer el informe con objetividad. "Le vamos a escuchar con mucha atención", le dice uno al entrar. "No pido nada más”, responde él (01:04:41). Peter no se inmuta, pero él y sus adláteres, bien organizados, no están por la labor de permitir que hable para que no estropee sus mentiras y falsedades.

Soterradamente, se ha creado un ambiente en contra del doctor para que sus palabras, con la verdad sobre el balneario, no lleguen a oídos de la gente. Un vecino de la camarilla del alcalde afirma que "hay opiniones diversas". Thomas, sorprendido, responde que "todavía no sabe qué va a decir" (01:05:56). Algunos empiezan a crear alboroto. Pero al plan manipulador, no le conviene ir muy deprisa, el enemigo no debe quedar herido, porque podría volver a levantarse. Hay que destruirlo totalmente. Por eso Peter retoma el control de la situación y dice con gesto magnánimo: "Creo que sería democrático elegir un moderador" (01:06:19). Para dar una imagen de persona ponderada, frente a los que gritan, y de político democrático y respetuoso, no quiere ejercer él de moderador, como indican algunos, y sugiere que sea el periodista Sr. Aslaksen.

3. La primera fase del plan manipulador de Peter está cumplida. Ahora viene la segunda, que implica halagar el oído de los ciudadanos con promesas de bienes sin fin y advertirles de los graves perjuicios que pretende ocasionarles el doctor, movido exclusivamente por sentimientos innobles (01:07:45). Tal como tenía planeado, consigue fácilmente soliviantar los ánimos de los presentes en contra del científico Thomas, a quien no permiten ni dirigirse a la muchedumbre.

Un experto manipulador, como Peter, obra siempre taimadamente para que nadie descubra sus verdaderos motivos. Va siempre a favor de las apetencias -en este caso, la prosperidad para todos gracias al balneario-, porque así es fácil el engaño. A la vez, se cuida de descalificar a los que 
no le sigan el juego, para que queden neutralizados, como hace con Thomas y el contenido del informe.

El alcalde concluye con una pregunta retórica que anula cualquier vestigio de que la verdad pueda salir a luz porque queda totalmente descalificada: “ ¿Tiene alguien de nosotros el derecho democrático de criticar los pequeños defectos del balneario?, ¿a exagerar los errores fácilmente reparables y a intentar publicar esas difamaciones para que todo el mundo lo sepa?" (01:11:03).

4. A continuación, en el embate definitivo, aparecen las amenazas y el golpe de fuerza: "Debemos trazar una línea, y a todo aquel que decida cruzar esa línea, nosotros, el pueblo, debemos agarrarlo por el cuello y decirle: Eso no puedes decirlo" (01:11:41).

Peter ha obtenido una victoria rotunda. El mal y la mentira han vencido al bien y la verdad (Cortina, 2013).

\subsubsection{Comunidad versus masa}

Thomas, refiriéndose al sombrero de alcalde, le dice a Peter: "En una democracia, este sombrero no te pertenece, pertenece al pueblo. Pasa de unos a otros. No puedes dar órdenes. No, hasta que el pueblo decida" (00:57:51 - 00:58:09). Tiene razón, pero olvida que vivir en un régimen democrático no supone tener garantizada la libertad, porque el manipulador sabe ocultar sus torpes intereses, mientras presenta un aspecto magnánimo y bienhechor, como Peter Stockmann, y hacerse con el poder sobre el pueblo, sin que este se aperciba de que está siendo manipulado.

El afanoso de dominio puede manejar al pueblo para convertirse en un auténtico autócrata, sin dejar la apariencia de actuar democráticamente. Para ello, lo primero que debe hacer es convertir la comunidad en una mera masa. La diferencia entre ambos términos no es cuantitativa, sino cualitativa. Un gran número de personas que se manifieste en la calle con un sentido bien definido y reflexionado constituye una comunidad, no una masa.

Por el contrario, un pequeño grupo de personas relacionadas por intereses egoístas forma una "masa", una mera suma de individuos con intereses co- 
munes, y esta, aunque pueda parecer fuerte y temible, es internamente débil. Como "masa", tales individuos pueden ser altamente destructivos, pero, a pesar de su fuerza arrolladora, en el fondo son extremadamente frágiles. No están unidos interiormente porque participen de valores elevados, sino que se asocian, se organizan, para alcanzar una meta de tipo práctico (conservar sus privilegios o aumentarlos, defenderse...). Un colectivo de personas, una "masa", es fácilmente manejado por un manipulador astuto como Peter, que fascina con el señuelo de ganancias inmediatas y fáciles.

Sin embargo, una comunidad, es decir, un auténtico pueblo, lo forman personas que comparten convicciones éticas valiosas. Por eso es inexpugnable; puede ser destruida desde fuera por la violencia-como Thomas y su familia- pero no dominada interiormente; cada uno conserva intacta su libertad interior y los valores que encarnan son indestructibles. Solo en una comunidad así, donde resplandezcan la verdad y la auténtica libertad, tiene sentido la democracia (Ayuso-Torres, 2007; Martínez-Martín, 2011).

Con esas claves se pueden entender las afirmaciones de Thomas: "El solo hecho de que haya una masa con forma humana no significa que sea el pueblo. Ese honor hay que merecerlo" (01:15:12). A la luz de esa diferencia establecida entre "pueblo" y "masa" se comprende que diga: "Estoy en contra de esa mentira de que la mayoría siempre tiene razón" (01:16:27). Lo que hace que un grupo tenga razón no es que sea una mayoría, sino que sea un pueblo cohesionado con ideales valiosos. Thomas cree en la democracia, pero fundamentada sobre sólidos principios éticos compartidos por todos. Si no es así, la voluntad de la mayoría se convierte justamente en lo contrario de la democracia, porque es el fruto de los ardides del manipulador. Por eso afirma con rotundidad que "La mayoría siempre se equivoca" (01:16:34). ¿Tenía razón la mayoría cuando quiso que crucificaran a Jesús? El ejemplo es totalmente pertinente, porque se trata de un hecho histórico de decisión de una masa manipulada. Dice la Escritura: "Los sumos sacerdotes y los ancianos lograron persuadir a la gente que pidiese la libertad de Barrabás y la muerte de Jesús" (Mt, 27,20); y también: "Los sumos sacerdotes incitaron a la gente a que dijeran que les soltase más bien a Barrabás" (Mc, 15,11). No era una comunidad, un pueblo bien trabado, quien gritaba, sino una masa manipulada taimadamente.

Thomas no tiene una visión aristocrática que le llevaría a creer que el pueblo no está preparado para tomar decisiones. Es Peter, el alcalde manipulador, 
quien dice que el individuo ha de subordinarse a la autoridad. Thomas es un demócrata convencido, pero con la exigencia de que sea un auténtico pueblo, con criterios éticos: "La mayoría nunca tiene razón si no hace lo que debe" (01:16:57). Esta es la clave: la mayoría tiene razón cuando hace lo que debe.

Acabada la reunión, todos están sublevados contra él. Finalmente, solo con el voto en contra del capitán Forster, la Asamblea declara al doctor Stockmann "enemigo del pueblo" (01:18:55).

2.2.5 Transición al tercer apartado: las fuerzas del mal han vencido (01:20:41 - 01:41:30)

La violencia desatada amenaza a Thomas y su familia. Manos anónimas apedrean su casa.

Al día siguiente comprobarán que se han quedado solos y que el cerco se estrecha peligrosamente: El cristalero no va a ir a arreglar las ventanas; el casero los echa de casa; Petra se ha quedado sin su trabajo en la escuela; a los niños los han insultado sus compañeros y llegan a casa con heridas de una pelea; al capitán Forster lo han despedido y no se pueden ir con él a América; y al mismo Thomas lo cesan de su cargo de médico.

Todavía los villanos van a intentar tentarlo para doblegarlo por fin. Lo han vencido externamente por la fuerza, pero no han conseguido derribar su entereza interior. Pretenden una victoria total:

- Peter le ofrece recuperar el trabajo si se retracta.

- El suegro de Thomas, Morten Kiil, ha comprado la mayor parte de las acciones del balneario aprovechando que han bajado de precio y le plantea una terrible disyuntiva: si cede a la presión y miente, su esposa heredará una gran fortuna; si se mantiene en su actitud de hombre veraz, él y su familia estarán condenados a la marginación y la miseria.

- Van a verlo el director y el editor del periódico. Saben que el suegro ha comprado las acciones, le piden perdón, le ofrecen su ayuda y le solicitan dinero para que subvencione el periódico. 


\subsection{Clímax y desenlace (01:41:31)}

La decisión es firme: la opción por los valores es más fuerte que todas las presiones.

Thomas hace salir de su casa a los últimos visitantes. El matrimonio se mira y sonríe. Están animados y comentan: "No vamos a huir. Esta es nuestra tierra" (01:43:00).

Como la imagen de apertura, la imagen de cierre es también el hogar de la familia de Thomas Stockmann, pero esta última es la inversa de la primera. Muestra el resultado del cambio enérgico que ha supuesto el drama que ha presentado la película. El gesto apacible se ha convertido en un gesto tenso. La puerta abierta a todos está ahora cerrada a cal y canto para protegerse de las agresiones del exterior. Así también lo da a entender la melodía que acompaña esta escena.

Sin embargo, aunque lo estén pasando mal, los Stockmann siguen constituyendo una familia feliz, porque: $a$ ) permanece el amor y $b$ ) no abdican de su actitud de adhesión a los grandes valores. Es decir, el villano y sus corifeos han hecho mucho daño y hasta se diría que han vencido porque han conseguido anular y aislar al único obstáculo para sus intenciones perversas. Pero no han podido destruir la libertad íntima de la persona. Thomas y su familia no se doblegan ante la razón de la fuerza y se mantienen firmes, adheridos a los grandes valores. Y estos son indestructibles, quedan fuera del alcance de las malas artes de los individuos. Una masa manipulada no es dueña de los valores ni tiene poder sobre ellos. Es una de las grandes lecciones que encierra el filme (Almacellas, 2004).

El hogar de los Stockmann sigue siendo un ambiente de amor y encuentro personal a pesar de todas las vicisitudes que están viviendo. Cierran su casa no por falta de solidaridad, sino para protegerse de los ataques de aquellos mismos a los que acogieron y ayudaron.

Nos parece innegable la gran labor formativa de todas las ciencias sociales para la humanidad, aunque algunas, por su acceso a un mayor número de personas y por su capacidad de hacer más accesibles, vivas y comprensibles las ideas tienen una eficacia mayor. En este caso, El enemigo del pueblo es un modelo que considerar en el mundo del teatro. Sin embargo, como obra 
cinematográfica también ha dejado meritoria huella, de ahí que la hayamos analizado desde la mirada pedagógica (Touriñán y Sanz, 2015). Asimismo, en esta propuesta educativa recomendamos la lectura de la obra de Ibsen ${ }^{8}$, tanto a modo individual como en grupo y sugerimos el posterior desarrollo de un debate que servirá para reforzar el enriquecimiento del pensamiento analítico y la capacidad de autocrítica (Abad, 1981; Cavell, 2008; Nussbaum, 2012).

Si pudiéramos presenciar la obra de teatro ${ }^{9}$, sería una buena oportunidad para conocer, comparar y valorar las posibilidades educativas de las artes escénicas como el cine y el teatro, ya que estamos ante un guion cinematográfico perfectamente adaptado a una gran obra literaria (Spang, 1991; Vieites, 2016). Con ello, como docentes, tanto desde el ámbito formal como el no formal, intentamos formar a las personas para el universo donde viven, hacer presente en la educación casi todo lo que existe en el mundo a través de su representación cinematográfica y dramática (Méndiz, 1994; Snyder, 2010; Corrigan, 2011; Fontich, 2013); servirse del cine y del teatro para abordar de forma viva la educación en valores; y, sobre todo, en este caso, a partir de la etapa adolescente, aprovechar el cine, por su conexión con el conocimiento, con la emoción, con el sentimiento, con la belleza, con el arte y no olvidar que la meta educativa es la persona en su totalidad (Gutiérrez, Pereira y Valero, 2006; Pereira, 2010; Camps, 2011; García- Amilburu y Landeros, 2011; Pérez-Millán, 2014; Lara, Ruíz y Tarín, 2018).

\section{REFLEXIONES FINALES}

El enemigo del pueblo es una historia fílmica conmovedora, bien estructurada y sobre todo asombra cómo la obra de Ibsen en la que se basa, escrita en 1882, desarrollada en un pueblo noruego, pueda ser ahora tan moderna y vigente como en su época o incluso más, pues la crítica social y política que retrata es de una actualidad y universalidad sorprendente (Duro et al., 2018).

${ }^{8}$ Ibsen, H. (2016). Un enemigo del pueblo. Madrid: Losada.

${ }^{9}$ Abad, F. (1981). Un enemigo del pueblo, de H. Ibsen. Madrid: Radio Televisión Española. Obra de teatro. Recuperado de: www.rtve.es/alacarta/videos/estudio-1/estudio-1-enemigo-del-pueblo/861893/ (consulta: 5/10/2020). 
El filme es un recurso idóneo para el análisis de valores, así lo muestran situaciones que intentaban educar a la ciudadanía o hacer cumplir lo justo y también cómo el poder abusa y condena a quien no se pliega a él.

La película nos ofrece un modelo de familia donde se consolidan valores como respeto, amor, comunicación, unión, alegría, responsabilidad, justicia, solidaridad... Valores que ayudarán a que cada uno de sus miembros crezcan como personas capaces de convivir en contextos donde reine la libertad y la verdad ya que, como se viene afirmando desde hace tiempo, la familia sigue considerándose el primer agente de socialización de la humanidad.

A medida que el filme avanza, gracias a todos los elementos básicos de la cinematografía: localizaciones, decorados, iluminación, vestuario, maquillaje, composición (Fernández-Almoguera y López-López, 2020) y a los contundentes diálogos, a la adecuada ambientación y a la perfecta interpretación de los actores, se ponen en evidencia los verdaderos intereses de cada personaje y de los distintos estamentos sociales. Las representaciones iniciales están llenas de respeto y armonía, poco a poco van dando paso a escenas donde la mentira, el odio y otras actitudes intolerantes pasan a ser habituales, y provocan la inquietud, el surgimiento de incógnitas, la reflexión y los cambios de actitud en los espectadores.

Comprobamos cómo el análisis interpretativo de los personajes facilita el entendimiento de los valores y contravalores que los caracterizan (Camps, 2008): el doctor Stockmann, un hombre ético defensor de sus ideales, representa la libertad, la verdad y la coherencia (Hortal, 2002; Sanz y Escámez, 2013). El capitán George Forster evita la manipulación y toma decisiones acordes con sus criterios procurando el bien. Mientras que el señor Kiil no se implica, pero se vale de los otros para su beneficio. Igual que Peter Stockmann, con actitud interesada, agarrado a su cargo político sin velar por el bien común, asociado a la envidia, la manipulación y la mentira. Se enfrenta a su hermano y lleva al pueblo a la demagogia, la incompetencia y la corrupción, en vez de cuidar el bien y actuar con eficacia y honradez.

Los periodistas de La voz del pueblo, Hovstad, Billing y Aslaksen, en principio partidarios de una prensa veraz y libre, pronto cambian ante la implicación del alcalde y sus maniobras populistas unidas al soborno y contrario a la deontología y la democracia. 
Por último, se encuentra el pueblo, sin formación y fácil de manejar por parte del poder político que descalifica y destierra al doctor y a su familia por defender la verdad ante un grave problema de salud ciudadana.

Todo ello ayuda a comprender y sentir las escenas y mensajes más relevantes enmarcados en el inicio, el nudo y el desenlace del guion cinematográfico. Además, la propuesta educativa se completa con el análisis de la lectura de la obra y la representación teatral de Ibsen de cara a la formación moral del alumnado (Smith, 2011; Tabernero-Holgado y Perdiguero-Gil, 2011; Bokova, 2015; Jordán-Sierra y Méndez-Cestero, 2017; Unesco, 2017).

A partir del estudio realizado se podría continuar investigando en la teoría, política o práctica educativa, así como en la aportación de técnicas de enseñanza de valores y otras estrategias de educación moral.

Para finalizar, tanto en estas páginas como en la labor que llevamos a cabo durante años, nuestro esfuerzo se ha dirigido a facilitar que el mundo de la educación aproveche tanto como puede aportarle el cine. En muchas de sus obras el cine es arte y hace más accesible la belleza que otros lugares o medios. Y la mera contemplación de la belleza siempre ejercerá una influencia educativa en las personas. Pero, además, la vida que se reproduce en la pantalla es un valioso material para la reflexión y también un estímulo para quienes están desarrollando su personalidad. En este sentido, si hemos despertado o alimentado la preocupación por hacer más presente el cine en la educación, nuestra labor habrá encontrado la mejor de las recompensas.

\section{BiBLIOGRAFÍA}

Almacellas, M. á. (2004). El cine como instrumento educativo en el ámbito de la familia y en el de la escuela. Educadores: Revista de renovación pedagógica 211, 327-339.

Almacellas, M. Á. (2015). Seguir educando con el cine. Madrid: Digital Reasons.

Anderson-Imbert, E. (1946). Ibsen y su tiempo. Buenos Aires: Yerba Buena. Ayuso-Torres, M. (2007). Valores, pluralismo y comunidad política. Verbo. Revista de formación cívica y de acción cultural, según el derecho natural y cristiano 457-458, 561-570. 
Boкоva, I. (2015). Replantear la educación. ¿Hacia un bien común mundial? París: Unesco.

CAmps, V. (2008). Creer en la educación: la asignatura pendiente. Barcelona: Península.

CAmps, V. (2011). El gobierno de las emociones. Barcelona: Herder.

Cavell, S. (2008). El cine, ¿puede hacernos mejores? Buenos Aires: Katz.

Corrigan, T. (ed.) (2011). Film and literature. An introduction and reader. Londres: Routledge.

Cortina, A. (2013). ¿Para qué sirve realmente la ética? Barcelona: Paidós.

Duro, E. A. et al. (2018). El impacto social de la comunicación en las epidemias: perspectivas bioéticas y de la salud pública. Revista Iberoamericana de Bioética 7, 1-16. Recuperado de: https://revistas.comillas.edu/index. php/bioetica-revista-iberoamericana/article/view/8374/8346 (consulta: 5/10/2020).

FernándeZ-Almoguera, M. C. y LóPEz-LóPEz, E. (2020). La escenografía en el cine. Making Of. Cuadernos de Cine y Educación 151, 9-12.

FonTich, X. (2013). Cine y literatura en secundaria para trabajar la interpretación literaria conjuntamente. Lenguaje y textos 37, 121-131.

García-Amilburu, M. y Landeros, B. (2011). Teoría y práctica del análisis pedagógico del cine. Madrid: Editorial UNED.

Gutiérrez, M. C., Pereira, M. C. y Valero, L. F. (2006). El cine como instrumento de alfabetización emocional. Teoría de la Educación. Revista Interuniversitaria 18, 229-260.

Hortal, A. (2002). Ética general de las profesiones. Bilbao: Desclée De Brouwer.

JordÁn-Sierra, J. A. y Méndez-Cestero, J. (2017). Rasgos esenciales de los profesores excelentes en su relación con los alumnos tras el visionado de películas pedagógicamente valiosas. Estudios sobre Educación 33, 103-126.

Lara, F., Ruiz, M. y Tarín, M. (2018). Cine y educación. Madrid: Academia de las Artes y las Ciencias Cinematográficas de España.

LóPEz-Quintás, A. (2001). La tolerancia y la manipulación. Madrid: Rialp.

López-Quintás, A. (2009). Descubrir la grandeza de la vida. Bilbao: Desclée De Brouwer. 
Martínez, E. (2016). Por una formación cultural emancipadora, en F. Esteban (ed.), La formación del carácter de los maestros (pp. 57-73). Barcelona: Edicions de la Universitat de Barcelona.

Martínez-Martín, M. (2011). Educación, valores y democracia. Revista Educación número extraordinario (1), 15-19.

Méndiz, A. (1994). Diferencias estéticas entre teatro y cine. Hacia una teoría de la adaptación dramática, en F. Eguiluz, R. Merino, V. Olsen y E. Pajares, Transvases: Literatura, cine, traducción (pp. 331-340). Vitoria: Universidad del País Vasco. Facultad Filología Inglesa y Alemana. Recuperado de: https://n9.cl/zuoog

Nussbaum, M. C. (2012). Crear capacidades. Propuestas para el desarrollo humano. Barcelona: Paidós.

Orellana, J., Almacellas, M. á. y Watt, N. (2019). Manual de crítica de cine. Madrid: CEU Ediciones.

Pereira, C. (2010). El cine como ámbito de educación. La educación "por" y "para” el cine. En J. M. Touriñán (dir.), Artes y Educación. Fundamentos de Pedagogía Mesoaxiológica (pp. 238-262). La Coruña: Netbiblo.

Pérez-Millán, J. A. (2014). Cine, enseñanza y enseñanza del cine. Madrid: Morata.

Sanz, R. y Escámez, J. (2013). Pensar y hacer hoy ética profesional. Edetania: estudios y propuestas socio-educativas, 43, 203-215.

Sмith, J. E. (2011). The meaning of teaching from the perspective of exemplary and experienced teachers. Tesis. The Pennsylvania State University.

SNyder, B. (2010). ;Salva al gato! El libro definitivo para la creación de un guión. Barcelona: Alba Editorial.

SPANG, K. (1991). Teoría del drama. Lectura y análisis de la obra teatral. Pamplona: EUNSA.

Tabernero-Holgado, C. y Perdiguero-Gil, E. (2011). El cine y las dimensiones colectivas de la enfermedad. Revista de Medicina y Cine 7(2), 44-53.

Touriñán, J. M. y SÁEz, R. (2015). La mirada pedagógica. Teoría de la educación, metodología y focalizaciones. Santiago de Compostela: Andivira.

Unesco (2017). Educación para los Objetivos de Desarrollo Sostenible. Objetivos de aprendizaje. París: Unesco.

Vieites, M. F. (2016). Teatro y Comunicación. Un enfoque teórico. Signa, Revista de la Asociación Española de Semiótica 25, 1153-1178. 


\section{Referencia filmográfica}

Schaefer, G. (1978). El enemigo del pueblo, EE. UU., 90 minutos. DVD. Madrid: Crisesda Films, S. L. 